\title{
Causes that Effect the Mobility of Albanian Healthcare Personnel
}

\section{Doi:10.5901/ajis.2015.v4n2s2p160}

\author{
Gazment Koduzi ${ }^{1}$, MD, PHD \\ Ardita Kongjonaj2, MSC \\ Vladimir Lazarevik², MD, MSC \\ ${ }^{1}$ Albanian University, Senior Researcher Healthgrouper \\ ${ }^{2}$ Senior Researcher Healthgrouper \\ Email: gako@healthgrouper.com
}

\begin{abstract}
The healthcare system is affected by massive migration of personnel, hence one third of the Albanian population leave abroad. The migration of healthcare personnel in Albania is becoming a phenomenon that might risk the stability of the healthcare system with it's upgrading intensity. It also contributes to lowering the quality of services rendered and at the same time reduces the necessary transfer of knowledge to the younger generations. According to the Order of Physicians of Albania, 170 Medical doctors from 2009 until 2014 have asked for certificate of "Good standing" in order to apply for a job abroad. Qualitative research performed during last year, outlines and frames the problems and causes for the migration in five basic categories: economic, professional, political, personal and social factors for migration, including questions concerning the index of satisfaction for the profession. In order to respond to the objective of the study, a qualitative approach through focus groups with experienced and young professional was considered. The aim of this paper is to understand the "push" factors which affect the mobility of Albanian healthcare personnel. The need for higher income and professional development are the main causes of migration of healthcare workers in Albania in the past several years. Doctors are exposed to threats, verbal and physical attacks and generally do not feel safe at their workplace as consequence job satisfaction is reduced.
\end{abstract}

Keywords: health personnel, migration, social status, professional development, higher income

\section{Introduction}

As one third of Albanian population leave abroad (Nurja 2011), healthcare system is one of the sector affected by massive migration of personnel.The migration of healthcare personnel in Albania is becoming a rising phenomenon that can jeopardize the stability of the healthcare system with its rising intensity. It also contributes to the lowering of quality of services rendered and at the same time reduces the necessary transfer of knowledge to the younger generations. According to Order of Physicians of Albania there were 170 Medical doctors from 2009 until 2014 that asked for certificate of "Good standing" in order to apply for finding a job abroad. According to the Order of Nurses of Albania there were 80 nurses working in their profession in different countries, mainly in Italy, Greece and England.

\section{Methodology}

A qualitative research was performed during last year, through focus groups discussion and interviews with policy makers and key performers thatoutlineand group the problems and causes for the migration in five basic categories: economic, professional, political, personal and social factors for migration, including questions concerning the index of satisfaction for the profession. In order to respond to the objective of the present study, the focus groups were organized with young and senior medical professionals.

After a literature review to allow a better understanding of "push" and "pull" factors that affect migration, the process of data collection started through the elaboration of 2 focus groups.

Focus groups discussions held with two groups of participants (12 in total), one with medical doctors (young employed doctors and senior - employed doctors). The age structure was: under 31 - for the first and 39 - 45 for the second group.

Key persons from Ministry of Health, Order of Physicians, Order of Nurses, Head of National Centre for Continues Medical Education, Ministry of Education were posed to pre structured interview. 
Table 1. Focus groups composition

\begin{tabular}{|clcll|}
\hline Focus group & Specialty & Age & Gender & Employment status/Place of work \\
\hline MD -1 & Gastro-hepathology & 29 & Female & General hospital \\
\hline MD -1 & Ophthalmology & 29 & Male & Employed \\
\hline MD -1 & Gastro-hepathology & 28 & Male & General hospital \\
\hline MD -1 & Gastro-hepathology & 30 & Female & General hospital \\
MD -1 & Alergology & 30 & Female & Private hospital \\
\hline MD -1 & Gastro-hepathologyspecialist & 30 & Female & Employed \\
MD -2 & Neurology & 39 & Male & General Hospital \\
MD -2 & Cardiology & 45 & Female & General Hospital \\
MD -2 & Laboratory physician & 43 & Female & Maternity hospital \\
MD -2 & Obstetrics-gynecology & 37 & Female & Maternity hospital \\
MD -2 & Family doctor & 45 & Male & Primary Health Center \\
MD -2 & Family doctor & 45 & Male & Primary health center \\
\hline
\end{tabular}

\section{Findings}

Based on the interviews of young professionals "push" factors that motivate them to leave Albania were: professional development and working conditions, as the most important reasons. They stated that lack of employment and even if they are lucky to find a job, low salary obliges them to see for working possibilities abroad.

As push factors were mentioned: low payment (absolute and/or relative), poor working conditions, lack of resources to work effectively, limited career and development opportunities, unstable work environment, economic instability (Buchan \& Sochalski, 2004). Similarly, the senior doctors mentioned low salary, low esteem of doctor's status and lack of awards for good performance as main reasons to go and work abroad.

Average salary in Albania in 2014 was 378 Euro per month, which is very low comparing with average salary in developed countries. On the other hand senior doctors consider poor working conditions as obstacle to apply their knowledge and expertise.

Both categories of doctors, young and senior consider low salaries as push factor for migrating abroad, but they see this factor as an obstacle to reach their scope. In one hand, basic needs and living conditions for senior doctors, on the other hand continues education and start their own life for young doctors.

Professional reasons are very important for doctors to consider migration abroad. Young doctors have difficult approach to specialization, no access to real practice in the department set and lack of cooperation from senior professionals - all reasons considered as important to migrate in other countries where they can develop professional skills in proper way. Lack of medical equipment and medicine, bad infrastructure and working conditions are seen as professional obstacles by senior doctors to practice their knowledge. Whether, lack of knowledge update through trainings and lack of possibilities for further capacity building are seen as professional reasons for considering migration by both young and senior doctors.

Albania is a transition country and political parties have considerable influence in all areas of the social life. Senior doctors state political influence leads to pressure in their job and further continuum professional engagement which can make them considering migration abroad.

Taking into consideration all factors mentioned above as economical, professional and political, senior doctors would not recommend profession to younger generations. On the other hand, young doctors would strongly recommend it.

Young doctors also think that there should be a decrease of medical student's graduates in order to have more possibilities for specialization and continued professional training. Health reforms should aim to put meritocracy in place in order to motivate skilled doctors to stay and work in Albania. Senior doctor's state improvement of working environment and promotion without political pressure will make them stay and work in Albania and make more attractive doctors profession for future generations. Both categories of doctors, state the increase of wage as an important factor to keep them to contribute in healthcare system in Albania.

Migration may be a symptom of deeper problems in health systems, such as the challenges of retaining health professionals and improving workforce planning to reduce over- or undersupply (Buchan 2008). The President of Medical Chamber stated that there is no plan from Ministry of Health to define number of doctors are needed in every districts, how many doctors should follow faculty of medicine and get specialized. So, there is no study about the need of health system for medical doctors, as consequence there is no study to define number of students to be enrolled in faculty of medicine. Oversupply of the health market with healthcare workers is mentioned even by the President of the Order of 
Nurse bringing in focus that every year are graduated more nurses that needed in the Albanian healthcare system.

According to our study, there are needed 600 nurse yearly, meanwhile are graduated 1400 students in public sector and 600 students in private sector. On the other hand the German Ambassador in Albania sees the "other side of the coin" by stating that:

"As the number of health workers in Albania surmounts the market need by far, the migration of health workers is not so much seen as a "brain drain" rather than an opportunity to relieve domestic unemployment, to open new opportunities for the young unemployed, to generate remittances and to hope for the return of some of the health workers after having gained valuable knowledge abroad."

There are 271 doctors working in OECD ( Dumont \& Zurn, 2007) but the president of the Albanian Medical Chamber stated that during the last ten years, around 800 certificates of "Good Standing" have been issued to medical doctors. The number of certificates in Albania in 2013-2014 is issued to just 178 graduated medical doctors and nurses.

The age structure of emigrating health professionals is a particular concern, as young professionals are most likely to seek professional opportunities abroad, leaving behind an increasingly ageing workforce. The main reasons for leaving the country are unemployment, poor evaluation of the profession, and lack of opportunities for career advancement and further education.

According to a senior representative at Ministry of Health, the reasons why health professionals migrate do not even differ from others key informers. Hence, the first reason is low salary and then working conditions, and the most important professional development.

Motivational factors for health professionals are undoubtedly diverse, not only in our country but worldwide. Therefore looking at the same situation e.g in Lithuania, financial incentives and management issues are the main factors (Padaiga , Pukas \& Starkienw, 2014).

Ministry of Health representative stated that doctors don't have good salary that their profession deserves, which is hard to reach actually in health system. They have more qualification and training possibilities with better standards. There is a present political influence in finding a job, but even for professional development career. Doctors migrate abroad in order to practice their profession in better working conditions.

\section{Conclusions}

Migrant health professionals are usually faced with a combination of economic, social and psychological factors plus family choices. They consider migration when they expect this move can improve their professional and economic situation. In many studies and publications as push factors are identified: low salaries, poor working conditions and lack of professional opportunities, while demand for health professionals in destination countries in combination with higher payment, better working conditions and professional development opportunities act as pull factors (Buchan 2007).

The problems with migration of health workers in the countries are becoming very current. The consequences lay on the quality of the health system, the stimulating effect on the generations that are likely to study medicine, on the know-how transfer. Also, it can be seen in losing the government's investment in education of these highly profiled workers, in taxes that the government would lose on the basis of the salaries etc.

In Albania, the Ministry of Health recently called all the migrated doctors to come back, promising them better working conditions. But there is need for more than a "call" for this medical staff to live their higher salaries and better opportunities to come back home. There is a need for more scientific and policy relevant approach to this problem. However, this process must start and developed in the best way in order to limit the negative consequences of the "brain drain".

\section{References}

Buchan J, Sochalski J. 2004. "Nurse migration: trends and policy options". WHO Bulletin, Vol. 82. No.8, pp 587-594

Buchan J. 2008. How can the migration of health service professionals be managed so as to reduce any negative effects on supply? Copenhagen: WHO Regional Office for Europe

Buchan J. 2007. "Health worker migration in Europe Policy issues and options" London: HLSP Institute

Dumont JC and Zurn P .2007. Immigrant health workers in OECD countries in the broader context of highly skilled migration. International Migration Outlook: Sopemi 2007 Edition

Nurja I, 2011.Albania-Preliminary results of the population and housing Census 2011. Tirane: Mediaprint

Padaiga Ž ,Pukas M and Starkiene L, 2014, "Health professional migration in Lithuania: why they leave and what makes them stay", Health Professional Mobility in a Changing Europe, Volume II, pp 155-176. 